\title{
Running on age in a 15-km road run: minor influence of age on performance
}

\author{
Floortje Celie • Miriam Faes • Maria Hopman • \\ Anton F. H. Stalenhoef • Marcel G. M. Olde Rikkert
}

Received: 17 January 2010 / Accepted: 17 February 2010/Published online: 7 March 2010

(C) The Author(s) 2010. This article is published with open access at Springerlink.com

\begin{abstract}
The importance of exercise in the elderly is widely recognized, but data on performances and drop-out in short running contests are lacking. This hinders stimulation and coaching of elderly persons in active aging. The aim of the study was to determine age-related changes in running performance in the most popular Dutch road run, and how this is influenced by gender, training, and increased participation rate over the last decade. This is a retrospective analysis of 194,560 participants of a 15-km run from 1995 to 2007. Multiple regression analysis of running time by age, gender, and training was performed. Trends in participation were examined by chi-square tests and ANOVA. Trends in running time and speed were examined by $t$ tests. With aging, running time increased with $0.20 \%$ per year $(P<0.001)$. Running time was on average $13 \%(P<0.001)$ shorter in men than in women and was $15.7 \%(P<0.001)$ shorter in participants who trained on a regular basis. Decline in performance with age was $5.9 \%$ larger for men than women $(P<0.01)$ and $4.5 \%$ larger for trained than untrained participants $(P<0.01)$. Over the last decade, participation numbers increased most for
\end{abstract}

Manuscript was presented at the British Geriatrics Society Spring Meeting, Bournemouth Great Britain, April 2, 2009.

F. Celie · M. Faes · M. G. M. O. Rikkert $(\bowtie)$

Department of Geriatric Medicine,

Radboud University Medical Centre Nijmegen, code 925,

PO Box 9101, 6500 HB Nijmegen, The Netherlands

e-mail: M.Olde-Rikkert@ger.umcn.nl

M. Hopman

Department of Physiology,

Radboud University Medical Centre Nijmegen,

Nijmegen, The Netherlands

\section{A. F. H. Stalenhoef}

Department of Internal Medicine,

Radboud University Medical Centre Nijmegen,

Nijmegen, The Netherlands elderly ( $\geq 60$ years) and female participants, mean running performance declined with $9.9 \%(P<0.001)$. Drop-out number was low at all ages $(0.13-0.29 \%)$. It appears that aging has only minor negative influences on running performance, which can even be attenuated by training. Our data suggest that exercise by means of running is a safe and rewarding option for improvement of healthy and active aging.

Keywords Aging $\cdot$ Running $\cdot$ Performance $\cdot$ Exercise . Elderly

\section{Introduction}

Not much research has been carried out on the effect of aging on running performance, defined as running time or running speed, on short distance road races. Most research is based on longer distance road races, like marathons [14]. However, running marathons is rather exceptional among elderly persons, while many potentially could run short distances. To be able to convincingly stimulate and instruct people, reliable evidence on potential performances and safety of running on age is highly needed.

So far, literature suggests that there is a significant agerelated linear increase in running time starting at age 30-35 $[3,5-10]$, which accelerates beyond the age of $60-70[1-4$, $7,11,12]$. Marathon running times of men are $8-18 \%$ faster compared to women $[13,14]$. The decline in running performance with age seems greater for women than men due to biological influences [7, 9, 12, 13, 15].

In earlier work we showed that even (training for) long distance marches may decrease the rate of decline of $\mathrm{VO}_{2 \max }$ with advancing age $[16,17]$. Moreover, regular exercise is associated with a significant better physical function, improved cognition, a significant decrease in 
mortality and a better quality of life $[2,10,12,18-22]$. However, with growing older, participation in exercise decreases. Preconceived negative ideas on exercise opportunities and performances at older ages are associated with very low levels of physical activity, which jeopardizes healthy aging [23]. However, over the last years, running competitions seem to be able to attract more elderly people and running performances have significantly improved, especially for elderly women $[2,7,14]$.

To be able to improve evidence-based coaching in active aging, we conducted a study on the effects of aging, gender, and training on the running performances and drop-out rates in the most popular Dutch road run. This Nijmegen Seven Hills Run (see www.Zevenheuvelenloop.nl) is a $15-\mathrm{km}$ run in a woody area that attracts an increasing number of elderly persons, leading to almost 25,000 participants in 2008 , of whom 1,007 were older than 60 years.

\section{Methods}

\section{Research population}

The research population comprises all participants of the Seven Hills Run from 1995 to 2007, this means 194,560 persons. All participants who started in the competition were included. People registered for the run, but who did not participate, were excluded. Participants were grouped in 5 -year age categories. According to the Dutch Athletic union, a master athlete is aged over 35 years (up till 2007 this age limit was 40 years). To have uniform categories over the period of 12 years, we made one youngest category for participants younger than 40 years (divided into men and women) and two oldest categories: women $\geq 60$ years and men $\geq 65$ years.

\section{Data}

Running records from the Nijmegen Seven Hills Run from 1995 to 2007 were used. The 15.0-km Nijmegen Seven Hills Run covers seven short slopes in a hilly countryside. The first part is mainly uphill, the second part varying, and the last part mainly downhill. The organization of the Seven Hills Run provided all data and coded names of participants. The records included date of birth, gender, athletic club membership, and running times after 5,10 , and $15 \mathrm{~km}$. Running time was electronically measured by the Champion Chip ${ }^{\circledR}$ (ChampionChip Nederland, Nijmegen, The Netherlands), a chip attached to the shoe, which registers starting and finishing times. Training status was defined by membership of an athletic club. Competitive members were coded as trained, non-competitive, recreant members as less trained. Time was registered after 5, 10, and $15 \mathrm{~km}$.
Statistical analysis

Statistical analyses were performed using SPSS (version 14.0). Extensive data cleaning was performed. Subjects with missing values in running time after 5 and/or 10 or $15 \mathrm{~km}$ were excluded for analysis. The relationship between running performance and age was examined by means of multiple regression analysis, adjusted for sex and training status (ANCOVA). $\chi^{2}$-tests were performed to assess differences in participation numbers with passage of time in total, by age group, and between men and women. $t$ tests were performed to assess a period effect in running performance between age groups and between men and women. Differences at the $P<$ 0.05 level were considered statistically significant.

\section{Results}

Characteristics of the research population from 1995 to 2007

The youngest participant of the Nijmegen Seven Hills Run was 10 years, the oldest 80 years; $2.8 \%$ of the participants was $\geq 60$ years, this means 5,507 people, of which 77 people were $\geq 75$ years. The mean age of the participants increased significantly from 39.0 years (SD 9.2) in 1995 to 41.3 (SD 10.8) in $2007(P<0.001)$. Significantly more men $(77.7 \% ; P<0.001)$ than women and more untrained $(89.7 \%$, $P<0.001)$ than trained people participated

\section{Determinants of running time}

With aging mean running time over $15 \mathrm{~km}$ increased. The aging effect on $15-\mathrm{km}$ running time could be estimated as Time $(\min )=70.9+0.15^{*}$ age $($ years $)$. On average, aging 1 year increased running time $0.2 \%$, or $9 \mathrm{~s}(P<0.001)$. Mean running times were influenced by sex, training, and the year in which the run was ran. Mean running times were $13 \%$ faster for men $(P<0.001$; Table 1$)$. Trained participants on average had a $15.7 \%$ better performance compared to less trained participants $(P<0.001$; Figs. 1 and 2). The estimated mean running time corrected by age, sex, and training for $15 \mathrm{~km}$ is: $67.75+9,20 * \mathrm{sex}-$ $12,34 *$ training status $+0,20 *$ age, $29.3 \%$ (in which sex is 0 for men and 1 for women, training status is 0 for trained and 1 for untrained persons). Total variance in mean running time after $15 \mathrm{~km}$ was explained mostly by gender $(14.8 \%)$ and less by age and training status $(3.3 \%$ and $11.8 \%$, respectively, all $P<0.001$ ).

Participation rate over the last 12 years

Participation in the Nijmegen Seven Hills Run significantly increased over the period 1995-2007. In 1995, there were 
Table 1 Mean running time after $15 \mathrm{~km}$ by age and gender over the total of 12 runs

\begin{tabular}{|c|c|c|c|c|c|c|}
\hline \multirow[t]{2}{*}{ Age (years) } & \multicolumn{3}{|l|}{ Men } & \multicolumn{3}{|l|}{ Women } \\
\hline & $\mathrm{N}$ & Mean running time (minutes) & SD & $\mathrm{N}$ & Mean running time (minutes) & SD \\
\hline$<40$ & 63.532 & 73.12 & 10.25 & 21.329 & 83.31 & 10.16 \\
\hline $40-44$ & 27.942 & $74.10^{*}$ & 9.60 & 8.826 & $84.26^{*}$ & 9.08 \\
\hline $45-49$ & 26.519 & $75.27 *$ & 9.38 & 7.063 & $85.19^{*}$ & 8.97 \\
\hline $50-54$ & 18.370 & $77.05^{*}$ & 9.44 & 3.875 & $86.29^{*}$ & 8.98 \\
\hline $55-59$ & 9.690 & $79.01 *$ & 9.65 & 1.502 & $87.56^{*}$ & 9.08 \\
\hline $60-64$ & 3.482 & $80.74 *$ & 9.89 & 423 & 87.15 & 9.35 \\
\hline $65-69$ & 1.134 & $84.00^{*}$ & 10.26 & 110 & $90.56^{*}$ & 8.37 \\
\hline$\geq 70$ & 298 & $88.64^{*}$ & 10.56 & 44 & $92.37 *$ & 10.51 \\
\hline
\end{tabular}

$* P<0.001$ (the difference between this age group and the younger age group in this sex category was significant)

6,756 participants and in 2007 this number was 23,000 $(P<$ $0.001)$. The largest relative increases in participation numbers for both sexes were in the older age groups ( $\geq 55$ years), for example from 84 men aged 60 years and older in 1995 to 796 men in 2007. The number of participants has significantly grown from 1995 to 2007 with 1,101 to 6,125 for women, compared to an increase of 5,655 to 17,233 men $(P<0.01)$. The drop-out number was small. Between 1995 and 2007, 413 participants dropped-out (0.2\% of total number of participants). No difference in relative number of drop-out was seen between young ( $<60$ years) and old, nor between trained and untrained participants. Overall the number of drop-outs of participants over 60 years of age ranged from $0-0.7 \%$ per year of the run. Relatively

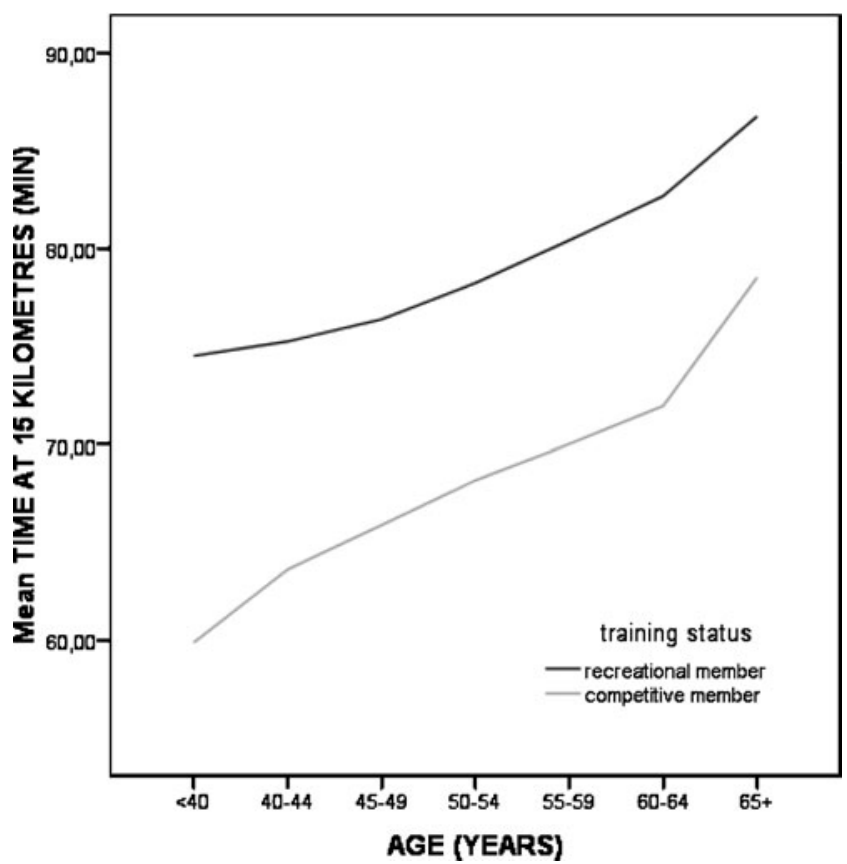

Fig. 1 Mean running time over $15 \mathrm{~km}$ by age and training status for men more women $(0.3 \%)$ than men $(0.2 \%)$ dropped-out $(P<.05)$. Cause of drop-out is not known.

Running time over the last 12 years

From 1995 to 2007, the mean running time after $15 \mathrm{~km}$ increased significantly with $9.9 \%$. In every age group, mean running time significantly increased, except for women $\geq 60$ years. On average, running time deterioration was $12-28 \mathrm{~s}$ from year to year for men and 17-34 s a year for women, ranging over age categories. Overall, most of the trained participants had constant mean running times between 2 years. Untrained participants had more variable performance results during the years.

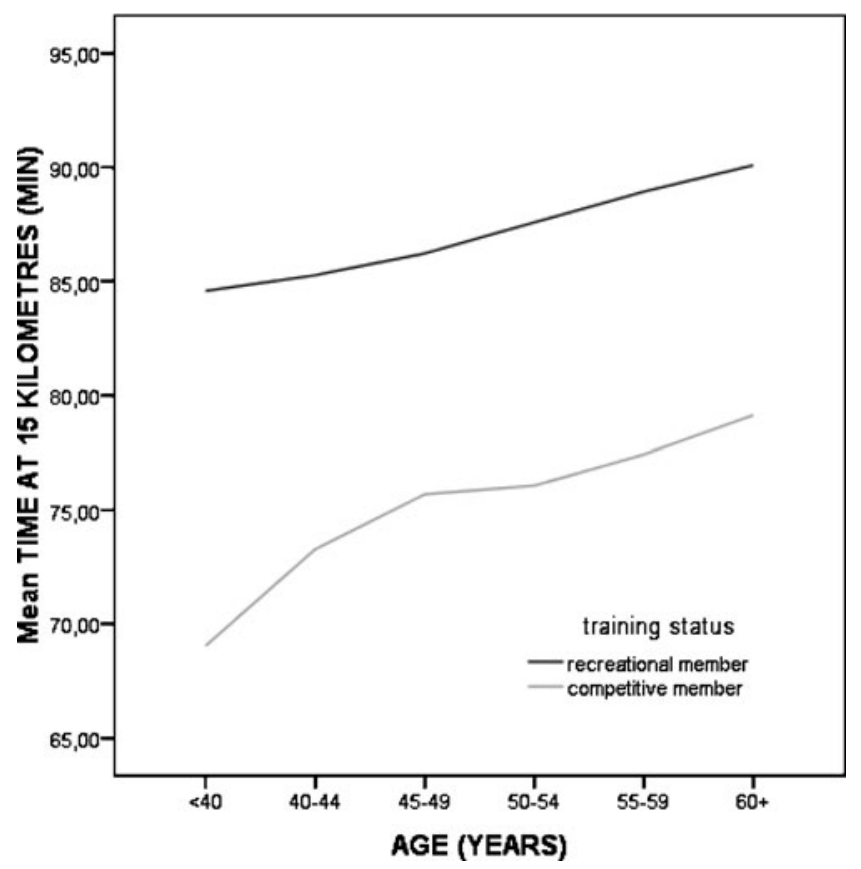

Fig. 2 Mean running time over $15 \mathrm{~km}$ by age and training status for women 
Running performance during the run

Men had significant faster mean running velocities than women in all parts of the run, but this difference decreased with aging. Men $<40$ years had mean running speeds 1.15 times faster than those of age-matched women $(P<0.01)$. Men $\geq 60$ years had mean running speeds only 1.10 times faster than those agematched women $(P<0.01)$. When the two groups of participants $<60$ years and $\geq 60$ years were compared, the percentage decline in running velocity with aging was significantly larger for men than women $(3.4 \%$ versus $9.3 \%$, $P<0.001)$ and significantly larger for trained than untrained participants $(P<0.001)$. However, trained participants of all ages had significant higher mean running speeds compared to age-matched untrained participants $(P<0.001)$.

\section{Discussion}

This study presents data showing that $15-\mathrm{km}$ running performance is influenced by age, gender, training state, and the year of the run, of which gender and training had the largest influence. Age effects on running speeds were rather small and the drop-out number among older persons is very low. During the last 12 years, the number of elderly participants increased most quickly, and their good running performances prove that elderly persons can very well train for, run, and finish in a $15-\mathrm{km}$ run. As a result of this increasing participation of elderly people mean running time increased, especially for untrained participants.

With aging, mean running time showed only limited decline of $0.2 \%$ per year. The decline in performance per year is smaller than described for marathon performances (10.5-14.8\% per decade) [2]. Running performance is influenced by several physiological variables, which can explain the decline in running performance with age. Most important are maximum aerobic capacity $\left(\mathrm{VO}_{2 \max }\right)$, muscle function, strength, and lactate threshold [8, 13, 15, 17]. Aging is associated with a decline in muscle mass, which becomes progressive beyond the age of $50[2,4,11,13,24$, 25]. The lactate threshold is reached at a faster rate, through which elderly people have a lower tolerance for strenuous physical activities [5, 7, 13, 26-28]. With growing old, cardiovascular parameters decline also, which causes decline in $\mathrm{VO}_{2 \max }[2,7,8,13-15,20,29,30]$. Training can increase $\mathrm{VO}_{2 \max }$ and the lactate threshold, even for elderly people $[5,7,10,13,16-18,20,21,25,29,30]$. Possibly, elderly participants may also show less motivation to reach their fastest running performance [5].

Velocity in men on average was $13.0 \%$ faster than in women, comparable to studies on marathons [3, 13, 14]. Difference in running performance between sexes is probably caused by a lower $\mathrm{VO}_{2 \max }[7,14,16,28]$ and less muscle mass for women compared to men $[12,14]$. Running performance differed $15.7 \%$ on average between training groups. Training effects on running speed were larger for men than for women, and aging had a larger negative effect on running speed for trained than untrained participants. This is consistent with the faster decline of $\mathrm{VO}_{2 \max }$ with aging in trained compared to sedentary elderly people, but running performance remains better in elderly trained than elderly untrained participants as has been shown for $\mathrm{VO}_{2 \max }[3,12,20,29]$. The increase in participation of elderly and women, was also described by Jokl et al. [2]. However, results on women and older people are still based on small groups. The participation number of the Seven Hills Run was restricted to a certain maximum for reasons of logistics. For the past years, the limit was increased with 1,000 individuals every year. During these years, the Seven Hills Run has changed from a small quite competitive run into the largest Dutch road run for a more varied (untrained) public.

Over the last decade, running performance decreased significantly for all participants with $9.9 \%$. Other studies showed better or constant running performance with passage of time $[2,7,14]$. Their conclusions were that improvements were possible by better tracks and more competition. For the studied years, the track of the Seven Hills Run was the same, but participation numbers increased, most in the older age groups. Probably the change in competitiveness, caused by less professionally trained participants, in combination with the increasing number of elderly, is the best explanation for higher average finish time.

Participants $\geq 60$ years had significant slower running times compared to younger participants, especially in the last part of the run, men even more than women. Other studies found a higher decline for women compared to men, but their results were possibly confounded by selection bias $[7,9,13,21]$. In our study, effect modification by age is possible, because in the male group, compared to women, more participants $\geq 65$ years were present.

Analysis of master running performance in athletic records has not frequently been carried out in the past. However, our data comprise a lot of information on performance, health, and aging. An advantage of using these records is that they are based on very large samples. Other studies examined maximum performance in master athletes and less trained older persons, which makes it very likely that these results are not representative for the average older person.

A limitation of this study is the lack of information concerning confounders, such as medical diagnoses, laboratory, and physiological parameters. With no upper limit for age, a considerable range of variability is allowed, within which the desired homogeneity of the exposure of the run may not be achieved. Because of this, exact age was used for most analyses. In addition, variable weather 
conditions could have influenced running performance, although these conditions are relatively stable.

It is unclear whether competitive membership of an athletic club is an accurate measurement instrument for training status, because other participants also prepared themselves for the run and no data were available for the duration and intensity of trainings within a club.

It is well evidenced that exercise has multiple positive effects on health and substantially contributes to healthy and successful aging. This study showed that age only has a minor effect on running times and that elderly people can very well run a $15-\mathrm{km}$ road race. Running performance is better in members of athletes clubs, also in the elderly participants. Overall, our data are promising and can stimulate and inform professionals in guiding elderly in running. Our results underline that running holds great opportunities to improve general health, because it is a simple, cheap, safe, and healthy means of active aging. Moreover, running and other exercises are equally available to all aging societies, which clarifies why the World Health Organization emphasizes this exercise as an important opportunity to reach active aging [31].

Acknowledgment We cordially thank the Seven Hills Run organization for giving us free access to their database.

Open Access This article is distributed under the terms of the Creative Commons Attribution Noncommercial License which permits any noncommercial use, distribution, and reproduction in any medium, provided the original author(s) and source are credited.

\section{References}

1. Conoboy P, Dyson R (2006) Effect of aging on the stride pattern of veteran marathon runners. Br J Sports Med 40(7):601-604

2. Jokl P, Sethi PM, Cooper AJ (2004) Master's performance in the New York City Marathon 1983-1999. Br J Sports Med 38(4):408-412

3. Leyk D, Erley O, Ridder D, Leurs M, Ruther T, Wunderlich M et al (2007) Age-related changes in marathon and half-marathon performances. Int J Sports Med 28(6):513-517

4. Trappe S (2007) Marathon runners: how do they age? Sports Med 37(4-5):302-305

5. Evans SL, Davy KP, Stevenson ET, Seals DR (1995) Physiological determinants of $10-\mathrm{km}$ performance in highly trained female runners of different ages. J Appl Physiol 78(5):1931-1941

6. Fair RC (2007) Estimated age effects in athletic events and chess. Exp Aging Res 33(1):37-57

7. Joyner MJ (1993) Physiological limiting factors and distance running: influence of gender and age on record performances. Exerc Sport Sci Rev 21:103-133

8. Maharam LG, Bauman PA, Kalman D, Skolnik H, Perle SM (1999) Masters athletes: factors affecting performance. Sports Med 28(4):273-285

9. Moore DH (1975) A study of age group track and field records to relate age and running speed. Nature 253(5489):264-265

10. Wilson TM, Tanaka H (2000) Meta-analysis of the age-associated decline in maximal aerobic capacity in men: relation to training status. Am J Physiol Heart Circ Physiol 278(3):H829-H834
11. Himann JE, Cunningham DA, Rechnitzer PA, Paterson DH (1988) Age-related changes in speed of walking. Med Sci Sports Exerc 20(2):161-166

12. Tanaka H, Seals DR (2003) Invited review: dynamic exercise performance in Masters athletes: insight into the effects of primary human aging on physiological functional capacity. J Appl Physiol 95(5):2152-2162

13. Baker AB, Tang YQ, Turner MJ (2003) Percentage decline in masters superathlete track and field performance with aging. Exp Aging Res 29(1):47-65

14. Cheuvront SN, Carter R, Deruisseau KC, Moffatt RJ (2005) Running performance differences between men and women:an update. Sports Med 35(12):1017-1024

15. Reaburn P, Dascombe B (2008) Endurance performance in masters athletes. Eur Rev Aging Phys Act 5(1):31-42

16. de Wild GM, Hoefnagels WH, Oeseburg B, Binkhorst RA (1995) Maximal oxygen uptake in 153 elderly Dutch people (6987 years) who participated in the 1993 Nijmegen 4-day march. Eur J Appl Physiol Occup Physiol 72(1-2):134-143

17. de Wild GM, Peeters MP, Hoefnagels WH, Oeseburg B, Binkhorst RA (1997) Relative exercise intensity of long-distance marching (120 km in 4 days) in 153 subjects aged 69-87 years. Eur J Appl Physiol Occup Physiol 76(6):510-516

18. Astrand PO (1992) Physical activity and fitness. Am J Clin Nutr 55(6 Suppl):1231S-1236S

19. Buchner DM, Beresford SA, Larson EB, LaCroix AZ, Wagner EH (1992) Effects of physical activity on health status in older adults. II. Intervention studies. Annu Rev Public Health 13:469-488

20. Pimentel AE, Gentile CL, Tanaka H, Seals DR, Gates PE (2003) Greater rate of decline in maximal aerobic capacity with age in endurance-trained than in sedentary men. J Appl Physiol 94 (6):2406-2413

21. Tanaka H, DeSouza CA, Jones PP, Stevenson ET, Davy KP, Seals DR (1997) Greater rate of decline in maximal aerobic capacity with age in physically active vs. sedentary healthy women. J Appl Physiol 83(6):1947-1953

22. Yates LB, Djousse L, Kurth T, Buring JE, Gaziano JM (2008) Exceptional longevity in men: modifiable factors associated with survival and function to age 90 years. Arch Intern Med 168 (3):284-290

23. Sarkisian CA, Prohaska TR, Wong MD, Hirsch S, Mangione CM (2005) The relationship between expectations for aging and physical activity among older adults. J Gen Intern Med 20 (10):911-915

24. Deschenes MR (2004) Effects of aging on muscle fibre type and size. Sports Med 34(12):809-824

25. Faulkner JA, Larkin LM, Claflin DR, Brooks SV (2007) Agerelated changes in the structure and function of skeletal muscles. Clin Exp Pharmacol Physiol 34(11):1091-1096

26. Bearden SE (2007) Advancing age produces sex differences in vasomotor kinetics during and after skeletal muscle contraction. Am J Physiol Regul Integr Comp Physiol 293(3):R1274-R1279

27. Tanaka K, Takeshima N, Kato T, Niihata S, Ueda K (1990) Critical determinants of endurance performance in middle-aged and elderly endurance runners with heterogeneous training habits. Eur J Appl Physiol Occup Physiol 59(6):443-449

28. Woo JS, Derleth C, Stratton JR, Levy WC (2006) The influence of age, gender, and training on exercise efficiency. J Am Coll Cardiol 47(5):1049-1057

29. Katzel LI, Sorkin JD, Fleg JL (2001) A comparison of longitudinal changes in aerobic fitness in older endurance athletes and sedentary men. J Am Geriatr Soc 49(12):1657-1664

30. Systrom DM (2003) Exercise physiology. www.uptodate.com

31. Kalache A, Aboderin I, Hoskins I (2002) Compression of morbidity and active ageing: key priorities for public health policy in the 21st century. Bull World Health Organ 80(3):243-244 